\title{
Intervenção fonoaudiológica com professores: análise de uma proposta realizada à distância
}

\author{
Speech therapy with teachers: \\ analysis of education
}

\section{Terapia del habla con los maestros: el análisis de una propuesta hecha la distancia}

\author{
Leslie Piccolotto Ferreira* \\ Rafaela Valiengo de Souza* \\ Alessandra Rodrigues Souza* \\ Juliana Schulze Burti* \\ Mariane Maião Pereira* \\ Susana Pimentel Pinto Giannini* \\ Thelma Mello Thomé de Souza Pereira* \\ Bianca Martins Castro*
}

\section{Resumo}

Objetivo: analisar a impressão dos participantes de um curso inserido no Programa de Bem-Estar Vocal, destinado a professores da rede de um município, oferecido na modalidade de Educação à Distância. Método: para sensibilizar professores quanto às questões da voz, foi apresentado um curso na modalidade de Educação à Distância, numa rede municipal de ensino (40 horas divididas em três encontros presenciais, oito módulos, oito fóruns e oito avaliações). Participaram 257 professores que emitiram 592 relatos sobre esse curso. Esses dados foram categorizados e submetidos à análise descritiva por meio de frequências

*Pontifícia Universidade Católica de São Paulo - PUC-SP, São Paulo, SP, Brasil

Contribuição dos Autores:

LPF: Concepção do estudo; Metodologia; Revisão crítica; Elaboração do artigo; Orientação; RVS: Concepção do estudo; Metodologia; Coleta de dados; Elaboração do artigo; JSB e ARS: Concepção do estudo; Metodologia; Coleta de dados; MMP: Elaboração do Artigo; SPPG e TMTSP: Concepção do estudo; Metodologia; Revisão crítica; Elaboração do artigo; BMC: Concepção do estudo; Metodologia; Coleta de dados; Elaboração do artigo.

Endereço para Correspondência: Mariane Maião Pereira marimaiaop@hotmail.com Recebido: $28 / 12 / 2018$

Aprovado: 20/05/2019 
absolutas e relativas. Resultado: todos os módulos foram colocados em prática, e quanto ao conteúdo deles, o denominado Articulação e Ressonância registrou a maior frequência de apontamentos quanto a ter sido colocado em prática $(89,29 \%)$, assim como foi o que recebeu maior número de elogios $(25.30 \%)$. O módulo Voz no trabalho docente registrou $97.14 \%$ de sugestões. Conclusão: os achados registraram a necessidade de se realizar ajustes no Curso a ser oferecido a novas turmas, com maior ênfase em módulos cujo conteúdo exige maior entendimento conceitual e posterior realização de práticas. A modalidade EAD alcançou seu objetivo, propiciando um momento de escuta (registro) das necessidades do professor, assim como uma reflexão por parte dele sobre sua prática e ambiente de trabalho.

Palavras-chave: Voz; Distúrbios de Voz; Docentes; Educação à Distância.

\section{Abstract}

Objective: to analyze the impression of the participants of a course included in the Vocal Wellness Program, destined to teachers of the network of a municipality, offered in the modality of Distance Education. Method: to sensitize teachers about voice issues, a distance education course was presented in a municipal teaching network (40 hours divided into three face-to-face meetings, eight modules, eight forums and eight evaluations). A total of 257 teachers participated in the study. These data were categorized and subjected to descriptive analysis using absolute and relative frequencies. Result: all the modules were put into practice, and the content of one of them, known as Articulation and Resonance, registered the highest frequency of notes on being put into practice $(89.29 \%)$, as it was the one that received the greatest number of praise $(25.30 \%)$. The Voice module in the teaching work registered $97.14 \%$ of the suggestions. Conclusion: The findings showed the need to make adjustments in the Course to be offered to new classes, with greater emphasis on modules whose content requires greater conceptual understanding and subsequent implementation of practices. The Distance Learning mode achieved its goal by providing a moment to listen (record) to the needs of the teacher, as well as a reflection on part of the teachers with respect to their practice and working environment.

Keywords: Voice; Voice Disorders; Faculty; Distance, Education.

\section{Resumen}

Objetivo: analizar la impresión de los participantes de un curso insertado en el Programa de Bienestar Vocal, destinado a profesores de la red de un municipio, ofrecido en la modalidad de Educación a Distancia. Método: para sensibilizar a los profesores sobre las cuestiones de la voz, se presentó un curso en la modalidad de Educación a Distancia, en una red municipal de enseñanza (40 horas divididas en tres encuentros presenciales, ocho módulos, ocho foros y ocho evaluaciones). Participaron a 257 profesores que emitieron 592 relatos sobre ese curso. Estos datos fueron categorizados y sometidos a análisis descriptivo por medio de frecuencias absolutas y relativas. Resultado: todos los módulos fueron puesto en práctica, y en cuanto al contenido de ellos, el denominado Articulación y Resonancia registró la mayor frecuencia de apuntes en cuanto a haber sido puesta en práctica $(89,29 \%)$, así como fue el que recibió mayor número de apuntes elogios (25.30\%). El módulo Voz en el trabajo docente registró 97.14\% de sugerencias. Conclusión: los hallazgos registraron la necesidad de realizar ajustes en el Curso a ser ofrecido a nuevas clases, con mayor énfasis en módulos cuyo contenido exige mayor entendimiento conceptual y posterior realización de prácticas. La modalidad EAD alcanzó su objetivo, propiciando un momento de escucha (registro) de las necesidades del profesor, así como una reflexión por parte de él sobre su práctica y ambiente de trabajo.

Palabras claves: ; Trastornos de la Voz; Docentes; Educación a Distancia. 


\section{Introdução}

O professor, dentre os profissionais da voz, é o mais pesquisado na Fonoaudiologia, com registro de estudos, que vão desde a avaliação da voz, ao estabelecer prevalência de distúrbios vocais nessa classe profissional, até as relações entre voz do professor e trabalho docente ${ }^{1}$.

Dentre as pesquisas que traçam o perfil vocal desse profissional, fica evidente a alta prevalência de distúrbios vocais nessa categoria. Esses distúrbios são decorrentes de uma demanda vocal intensa em condições adversas quanto ao ambiente (presença de ruído, poeira, entre outros) ${ }^{2}$ acompanhados de múltiplos fatores intercorrentes relacionados à organização do trabalho (excesso de trabalho, indisciplina dos alunos entre outros) ${ }^{3,4}$.

Em levantamento realizado por Dragone et al. $(2010)^{1}$, apenas $14 \%$ das 500 fontes bibliográficas analisadas faziam referência a algum tipo de intervenção, realizada pelo fonoaudiólogo com professores. Certamente esse número se deve à difícil tarefa de delinear uma pesquisa de intervenção.

Dentre as intervenções realizadas pelo fonoaudiólogo, a maioria se refere às oferecidas na modalidade presencial ${ }^{5,6,7}$, e apenas mais recentemente há iniciativas de se usar a Educação à Distância $(\mathrm{EaD})^{9}$.

A EAD se apresenta como um possível caminho para aumentar o acesso de pessoas a uma determinada informação, as quais, normalmente, não teriam condições de frequentar cursos presenciais como é o caso da maioria dos professores, em função da demanda excessiva de trabalho. Porém, a educação à distância ainda enfrenta muitos desafios e considera-se importante conhecer os educadores envolvidos nesses processos de formação, suas expectativas, assim como suas motivações ${ }^{9}$.

Assim sendo, para sensibilizar professores quanto ao seu bem-estar vocal, considerando o grande número de professores em nosso país, propor uma ação à distância seria sem dúvida uma solução, pois assim é possível contemplar maior número de professores atuantes em diferentes regiões do país, possibilitaria ao professor adquirir conhecimento sobre a saúde e bem-estar vocal sem sair de casa, em horário conveniente, além de poder incorporar cada vez mais recursos da informática no universo do docente ${ }^{8}$.

Em 2005, a prefeitura do município de São Paulo iniciou o Programa Municipal de Saúde
Vocal, devido à grande demanda de distúrbios relacionados à voz constatada por professores desta rede municipal. O Programa consistia em oficinas ministradas por fonoaudiólogas da Secretaria Municipal de Saúde e até 2010 tinha atendido mais de 2.329 professores da Rede Municipal de Ensino ${ }^{10}$.

Em 2011, foi criado um grupo, com representantes da prefeitura deste município e de uma universidade, com a participação de docentes e discentes do Curso de Fonoaudiologia e do Programa de Estudos Pós-Graduados em Fonoaudiologia, para desenvolver uma ação de educação visando à promoção de saúde, denominado "Promovendo o Bem-Estar Vocal do Professor", com o objetivo de sensibilizar o docente quanto aos cuidados vocais, para minimizar os agravos à saúde, reconhecendo que a voz do professor é um de seus recursos pedagógicos, elemento de comunicação, de interação e, por conseguinte de ensino-aprendizagem.

A modalidade de Educação à Distância foi considerada como proposta de reestruturação para esse Programa, uma vez que, dessa forma, conseguir-se-ia atender maior número de professores da Rede Municipal de Ensino.

O grupo vem oferecendo a cada semestre o curso "Promovendo o Bem-Estar Vocal do Professor", com experiência de sete turmas até o momento (duas em 2014, duas em 2015, uma em 2016, uma em 2017 e uma em 2018). A cada encerramento de uma turma o processo é avaliado, considerando as questões relacionadas à forma ou conteúdo.

Dessa forma, este estudo se justifica por permitir encontrar falhas ou dificuldades no processo de uma determinada turma (quarta turma do segundo semestre de 2015), a partir da opinião dos próprios envolvidos, para, na sequência, buscar saná-las.

É importante destacar que neste momento, além de docentes e discentes do Curso de Fonoaudiologia, também representantes do Curso de Fisioterapia integram o grupo (um docente e um discente), propiciando maior discussão, principalmente por ocasião do módulo em que questões de corpo e voz foram discutidas.

Para a análise dos dados partiu-se da proposta de Zabala ${ }^{11}$ que diz que todo o processo de aprendizagem passa por três níveis: o primeiro denominado conceitual, em que são apresentadas definições e conceitos; a seguir o nível procedimental, momento em que se trabalha com o que se deve saber fazer, e nesse momento regras, técnicas, métodos, destrezas ou habilidades, e estratégias, entram em ação; e por 
fim os atitudinais, que vem a ser o colocar em prática, incorporar por questão de valores (princípio éticos), atitudes (tendência ou predisposição para agir de certa maneira) ou normas (padrões ou regras de comportamento obrigatórias aos membros de um grupo social).

A hipótese inicial é que ao analisar as questões de forma e conteúdo do curso apresentado, e principalmente avaliar quanto os participantes colocaram em prática as temáticas abordadas, aspectos que são mais veiculados na mídia possam ser mais bem entendidos e colocados em prática pelos professores, e que esses, pela alta demanda de trabalho, terão dificuldade para realizar as atividades propostas a cada módulo do Curso.

O objetivo deste estudo é analisar a impressão dos participantes de um curso inserido no Programa de Bem-Estar Vocal, destinado a professores da rede de um município, oferecido na modalidade de Educação à Distância.

\section{Métodos}

Esta pesquisa, de caráter observacional e descritivo, foi devidamente cadastrada na Plataforma Brasil e aprovada pela Comissão de Ética da Pontifícia Universidade Católica de São Paulo (CAEE: 52496715.9.0000.5482 e CEP: 1.409.960). Os participantes receberam esclarecimentos sobre os objetivos, riscos e contribuições deste estudo e assinaram Termo de Consentimento Livre Esclarecido (TCLE).

\section{Participantes do Curso}

Foram convidados, por meio de nota em Diário Oficial, professores da rede municipal de São Paulo, interessados em participar do Programa "Promovendo o Bem-Estar Vocal do Professor". Foram ofertadas 300 vagas, sendo 257 preenchidas. O Curso foi validado para fins de promoção e evolução na carreira dos professores, fato que provavelmente facilitou a adesão dos inscritos. A análise desta pesquisa contou com os 592 apontamentos, produzidos pelos 257 participantes.

\section{O curso analisado}

O curso "Promovendo o Bem-Estar Vocal do Professor", com duração de nove semanas, totaliza 40 horas, sendo oito horas realizadas por meio de três encontros presenciais e as demais, por meio de Educação à Distância (EAD). Esse é composto por oito módulos, oito fóruns de discussão e oito avaliações inseridos na plataforma Moodle.

Os três encontros presenciais são realizados no início, no meio e ao final do Programa, com distância de um mês entre eles e ocorrem nas dependências de uma Instituição de ensino superior, em local de fácil acesso aos professores inscritos.

Em especial, para a turma a ser aqui analisada, no primeiro encontro presencial, a proposta, funcionamento do curso assim como informações sobre o uso da ferramenta Moodle foram apresentados. No segundo, os professores puderam esclarecer as dúvidas advindas dos módulos realizados, e no terceiro e último, foi trabalhada uma série de exercícios de aquecimento e desaquecimento vocal, e ao final entregue um marcador de livro, com essas práticas detalhadas, para que os participantes pudessem realizá-las diariamente.

No Moodle, os oito módulos foram apresentados em oito semanas, permitindo que os participantes acessassem os anteriores até a finalização da Oficina, caso ainda necessitassem rever algum conteúdo. Para a elaboração do conteúdo desses módulos foi utilizado o programa PowerPoint e textos trazendo definições e explicações sobre as temáticas foram acrescidos de vídeos, para facilitar o entendimento. Textos complementares foram ainda disponibilizados para os interessados em aprofundar as informações dadas.

Ao final de cada um dos oito módulos foi disponibilizado um questionário composto por sete questões, que ao serem respondidas puderam constatar o entendimento referente à temática estudada. Cada módulo foi aberto sempre no mesmo dia da semana e, na sequência, o participante foi convidado a participar de um fórum. Nesse, duas questões foram apresentadas para sensibilizar o professor quanto à temática pertinente ao conteúdo de cada módulo.

A cada 30 participantes, foi destacado um tutor que acompanhou a turma durante todo o curso, participando dos fóruns, apresentando ou respondendo as questões.

O Quadro 1 ilustra o título, conteúdo, e questões levantadas e discutidas ao final de cada módulo, por ocasião dos fóruns que sempre foram gerenciados pelos tutores responsáveis. 
Quadro 1. Apresentação dos oito módulos, segundo título, conteúdo e perguntas feitas em cada Fórum.

\begin{tabular}{|c|c|}
\hline Módulo 1 & O que é Voz?" \\
\hline Conteúdo & $\begin{array}{l}\text { Neste módulo, foram abordadas questões referentes à produção da voz, buscando relacionar o uso da voz } \\
\text { com os aspectos emocionais e o trabalho docente, destacando-se a questão de que a voz é um importante } \\
\text { instrumento de trabalho e, portanto, precisa ser cuidada, além de dar ênfase no aspecto anatomofisiológico. }\end{array}$ \\
\hline $\begin{array}{l}\text { Perguntas } \\
\text { do Fórum }\end{array}$ & $\begin{array}{l}\text { 1a. Professor, você se vê como um profissional da voz? Por quê? } \\
2^{a} \text {. Você viu nesse módulo que a produção da voz depende de vários aspectos como respiraçãa, articulação } \\
\text { (dicção), ressonância. No seu caso qual desses aspectos é mais difícil de ser percebido? }\end{array}$ \\
\hline Módulo 2 & "Cuidados com a voz" \\
\hline Conteúdo & $\begin{array}{l}\text { Neste módulo, foi possível aprender que um dos fatores mais importantes para garantir o bem-estar da voz } \\
\text { é manter as pregas vocais bem hidratadas. Cuidados com a saúde geral, vestuário, horas suficientes de } \\
\text { sono e lazer, mudanças bruscas de temperatura, fumo, bebidas alcoólicas, ar condicionado, uso de sprays } \\
\text { e drops anestésicos são alguns dos fatores que esse módulo aborda. }\end{array}$ \\
\hline $\begin{array}{l}\text { Perguntas } \\
\text { do Fórum }\end{array}$ & $\begin{array}{l}\text { lado nesse módulo o que você percebe que interfere na sua voz? O que você } \\
\text { questão? } \\
\text { oodem interferir na produção vocal, qual deles você desconhecia? }\end{array}$ \\
\hline Módulo 3 & "Voz no trabalho docente" \\
\hline Conteúdo & $\begin{array}{l}\text { Neste módulo, os professores puderam ver que na sua atividade de trabalho docente existem condições } \\
\text { adversas tanto do ambiente físico como da organização do trabalho que podem interferir no bem estar de } \\
\text { sua voz como: ruído, poeira e pó de giz, produtos químicos de limpeza, ventiladores e ar condicionado, } \\
\text { número excessivo de alunos por classe, reformas na escola, excesso de trabalho, violência e indisciplina. }\end{array}$ \\
\hline $\begin{array}{l}\text { Perguntas } \\
\text { do Fórum }\end{array}$ & $\begin{array}{l}\text { 1a. Você se percebeu em alguma das situações citadas nesse módulo? O que você acha que pode ser } \\
\text { feito para tentar mudar as situações do ambiente físico e da organização do trabalho que podem estar } \\
\text { prejudicando a saúde dos trabalhadores de sua escola? } \\
2^{a} \text {. Na sua escola tem CIPA? Se sim, ela é atuante? O que tem feito? Se não, você acha interessante a } \\
\text { ideia da CIPA? Por quê? }\end{array}$ \\
\hline Módulo 4 & "Corpo, postura e voz" \\
\hline Conteúdo & $\begin{array}{l}\text { tância de termos uma boa postura corporal, principalmente durante a jornada } \\
\text { 5. Consiste ainda, de algumas práticas de alongamento que facilitam a emissão }\end{array}$ \\
\hline $\begin{array}{l}\text { Perguntas } \\
\text { do Fórum }\end{array}$ & $\begin{array}{l}\text { alguma parte mais tensa no seu corpo durante sua atividade profissional? O que você } \\
\text { horar? } \\
\text { apresentados nesse módulo, qual ou quais você colocou em prática? O que percebeu? }\end{array}$ \\
\hline Mód & "Resp \\
\hline Conteúdo & $\begin{array}{l}\text { Neste módulo, é possível aprender sobre a importância da respiraçã } \\
\text { da voz. O ciclo respiratório é composto por duas fases: Inspiração qu } \\
\text { dá pela contração do diafragma e dos músculos intercostais; Expiras } \\
\text { o relaxamento do diafragma e dos músculos intercostais. }\end{array}$ \\
\hline $\begin{array}{l}\text { Perg } \\
\text { do F }\end{array}$ & $\begin{array}{l}\text { a. Você já havia prestado atenção } \\
\text { a. Dos exercícios apresentados n }\end{array}$ \\
\hline Módulo 6 & "Articula \\
\hline Conteúdo & $\begin{array}{l}\text { Quando falamos, transformamos o som da voz em palavras por meio da articulação, isso favorece a } \\
\text { projeção vocal. } \\
\text { Neste módulo, os professores puderam aprender que para uma voz mais agradável e sem esforço é preciso } \\
\text { usar as cavidades ressoadoras (nariz, boca e faringe) de forma equilibrada. }\end{array}$ \\
\hline $\begin{array}{l}\text { Perguntas } \\
\text { do Fórum }\end{array}$ & $\begin{array}{l}1^{a} \text {. Como você percebe sua articulação? Percebe alg } \\
2^{a} \text {. Ao fazer os exercícios de articulação propos } \\
\text { ressonância? }\end{array}$ \\
\hline 7 & Expressiv \\
\hline Conteúdo & $\begin{array}{l}\text { Este módulo destaca a importância do corpo inteiro na comunicação. É o que chamamos de expressividade, } \\
\text { que pode ser verbal (recursos da fala e da voz) e não verbal (recursos do corpo). A utilização da } \\
\text { expressividade verbal e não verbal durante as aulas garante uma comunicação mais efetiva na atividade } \\
\text { docente. }\end{array}$ \\
\hline $\begin{array}{l}\text { as } \\
\mathrm{m}\end{array}$ & $\begin{array}{l}1^{\text {a }} \text {. Com relação aos recursos verbais e não verbais citados nesse módulo, quais você acha que são mais } \\
\text { usados em sala de aula? } \\
2^{\text {a. }} \text { Qual deles prende a atenção dos alunos? Você colocou em prática os exercícios mencionados? Como foi? }\end{array}$ \\
\hline Mód & "Voz e emoção" \\
\hline Conteúdo & $\begin{array}{l}\text { e módulo, vemos que as emoçães podem interferir no controle da respiração, no posicionamento vertical } \\
\text { aringe, no relaxamento das pregas vocais e dos músculos da faringe, laringe, pescoço e ombros. Todo } \\
\text { esse pode afetar a voz: a respiração se altera, o tom habitual varia, a articulação fica mais travada, } \\
\text { n vários parâmetros ficam alterados. }\end{array}$ \\
\hline & $\begin{array}{l}\text { cha que fatores estressores estão presentes no seu ambiente escolar? Se sim, o que você pode } \\
\text { ninimizar o estresse? } \\
\text { um fator que te faz ficar estressado e que não tem a mesma influência no seu colega de trabalho? }\end{array}$ \\
\hline
\end{tabular}




\section{Coleta de dados}

A pesquisa se propôs a analisar os relatos dos professores a partir das questões apresentadas pelos tutores nos fóruns (Quadro 1).

Cada relato discorrido pelos participantes em um determinado fórum estava registrado no site do curso e esses foram copiados um a um, em forma de texto, num documento do programa Microsoft Word. Para cumprir com os preceitos éticos, os nomes dos participantes foram removidos.

\section{Análise dos dados}

Numa primeira etapa, os relatos foram categorizados, considerando se eram específicos à forma ou ao conteúdo do curso. Em seguida, foram separados em quatro grupos denominados: Dúvidas, Aplicabilidade prática, Elogios e Sugestões. Essas categorias foram registradas na relação com cada um dos oito módulos, ou seja, um relato relacionado a sugestões sobre o curso poderia ser categorizado por ocasião da realização de qualquer um dos módulos e assim ele era contabilizado na coluna referente ao fórum do módulo em que o mesmo ocorreu.

Para efeito de análise estatística, os itens foram reorganizados em planilha do Microsoft Excel, momento em que na linha horizontal foram aloca- dos todos os módulos e na vertical as categorias: relato referente ao CONTEÚDO; relato referente à FORMA; relato de Aplicabilidade (subdividido em COLOCOU EM PRÁTICA e NÃO COLOCOU EM PRÁTICA e DIFICULDADE PARA COLOCAR EM PRÁTICA); relato referente a ELOGIOS; e SUGESTÕES.

Foi realizada a análise descritiva dos dados por meio de frequências absolutas e relativas. Paraa comparação entre os módulos, utilizou-se o teste de comparação de proporções com intervalos de $95 \%$ (IC95\%). Os dados foram digitados e analisados no programa Excel para Windows versão 10. Para ilustrar, alguns apontamentos serão trazidos no momento da discussão.

\section{Resultados}

Foram avaliados 592 apontamentos, produzidos por 257 professores que cursaram os oito módulos de EAD. (Tabela 1).

Destaca-se na Tabela 1 que na avaliação sobre CONTEÚDO, dos 35 apontamentos registrados, $31.43 \%$ foram para o módulo denominado $\mathrm{O}$ que é voz?, assim como a única menção a FORMA esteve associada a esse módulo.

Tabela 1. Número e percentual de apontamentos para os quesitos conteúdo e forma, segundo módulo.

\begin{tabular}{lcccc}
\hline \multirow{2}{*}{ Módulos } & \multicolumn{3}{c}{ Avaliações } & Forma \\
\cline { 2 - 5 } & \multicolumn{2}{c}{ Conteúdo } & $\mathbf{n}$ & $\mathbf{( \% )}$ \\
\cline { 2 - 5 } & 11 & $(31.43)$ & 1 & $(100.00)$ \\
\hline O que é voz? & 9 & $(25.71)$ & 0 & $(0.0)$ \\
Cuidados com a voz & 0 & $(0.0)$ & 0 & $(0.0)$ \\
Voz no trabalho docente & 1 & $(2.86)$ & 0 & $(0.0)$ \\
Corpo, postura e voz & 5 & $(14.29)$ & 0 & $(0.0)$ \\
Respiração & 8 & $(22.86)$ & 0 & $(0.0)$ \\
Articulação e Ressonância & 1 & $(2.86)$ & 0 & $(0.0)$ \\
Expressividade & 0 & $(0.0)$ & 0 & $(0.0)$ \\
Voz e emoção & 35 & $(100.00)$ & 1 & $(100.00)$ \\
\hline Total & & & & \\
\hline
\end{tabular}

Na Tabela 2, verifica-se que todos os módulos foram COLOCADOS EM PRÁTICA. Em média foram 1.35 indicações por módulo, variando entre 1 e 94 apontamentos. Observa-se que o módulo Articulação e Ressonância apresenta, considerando o total de apontamentos, ao mesmo tempo as maiores frequências de participantes que COLOCARAM
EM PRÁTICA o que foi apresentado (27.01\%), como daqueles que NÃO COLOCARAM EM PRÁTICA (48,15\%). O módulo Respiração foi o que registrou maior número de menções referentes a TER DIFICULDADE EM COLOCAR EM PRÁTICA com $89,29 \%$ dos apontamentos nessa categoria. 
Tabela 2. Número e percentual de relatos para os quesitos que colocou em prática ou não, e se teve dificuldade, segundo os oito módulos.

\begin{tabular}{lcccccc}
\hline \multirow{2}{*}{ Módulos } & \multicolumn{7}{c}{ Avaliações } \\
\cline { 2 - 7 } & \multicolumn{2}{c}{ Colocou em prática } & Não colocou em prática & \multicolumn{2}{c}{ Teve dificuldade } \\
\cline { 2 - 7 } & $\mathbf{n}$ & $\mathbf{( \% )}$ & $\mathbf{n}$ & $\mathbf{( \% )}$ & $\mathbf{n}$ & $\mathbf{( \% )}$ \\
\hline O que é voz? & 4 & $(1.15)$ & 0 & $(0.0)$ & 0 & $(0.0)$ \\
Cuidados com a voz & 4 & $(1.15)$ & 0 & $(0.0)$ & 0 & $(0.0)$ \\
Voz no trabalho docente & 9 & $(2.59)$ & 0 & $(0.0)$ & 0 & $(0.0)$ \\
Corpo, postura e voz & 83 & $(23.85)$ & 1 & $(3.70)$ & 0 & $(0.0)$ \\
Respiração & 74 & $(21.26)$ & 9 & $(33.3)$ & 25 & $(89.29)$ \\
Articulação e Ressonância & 94 & $(27.01)$ & 13 & $(48.15)$ & 3 & $(10.71)$ \\
Expressividade & 79 & $(22.70)$ & 4 & $(14.81)$ & 0 & $(0.0)$ \\
Voz e emoção & 1 & $(0.29)$ & 0 & $(0.0)$ & 0 & $(0.0)$ \\
\hline Total & 348 & $(100.00)$ & 27 & $(100.00)$ & 28 & $(100.00)$ \\
\hline
\end{tabular}

Quanto aos ELOGIOS, na Tabela 3 observa-se que dos 83 apontamentos, $25.30 \%$ foram para o módulo Articulação e Ressonância. Referente às
SUGESTÕES, 97.14\% foram para o módulo Voz no Trabalho Docente.

Tabela 3. Número e percentual de relatos para os quesitos elogios e sugestões, segundo os oito módulos.

\begin{tabular}{lcccc}
\hline \multirow{2}{*}{ Módulos } & \multicolumn{3}{c}{ Avaliações } \\
\cline { 2 - 5 } & \multicolumn{2}{c}{ Elogios } & $\mathbf{n}$ & Sugestões \\
\cline { 2 - 5 } & 12 & $(14.46)$ & 1 & $(1.43)$ \\
\hline O que é voz? & 6 & $(7.23)$ & 0 & $(0.0)$ \\
Cuidados com a voz & 3 & $(3.61)$ & 68 & $(97.14)$ \\
Voz no trabalho docente & 13 & $(15.66)$ & 1 & $(1.43)$ \\
Corpo, postura e voz & 8 & $(9.64)$ & 0 & $(0.0)$ \\
Respiração & 21 & $(25.30)$ & 0 & $(0.0)$ \\
Articulação e Ressonância & 18 & $(21.69)$ & 0 & $(0.0)$ \\
Expressividade & 2 & $(2.41)$ & 0 & $(0.0)$ \\
Voz e emoção & 83 & $(100.00)$ & 70 & $(100.00)$ \\
\hline Total & & & & $\mathbf{0}$ \\
\hline
\end{tabular}

A análise a seguir considera a proporção entre o número de apontamentos $(\mathrm{n}=592)$ e de participantes $(\mathrm{n}=257)$. Observa-se nas Figuras 1 e 2 que foram avaliados somente os quesitos presentes em mais de um módulo. Quanto ao CONTEÚDO houve diferença estatisticamente significativa entre o módulo O que é voz? Versus Corpo, postura e voz e Expressividade.

Referente ao quesito COLOCOU EM PRÁTI$\mathrm{CA}$, houve diferença estatisticamente significativa entre Voz e emoção versus os demais módulos (Figura 1). Também, observa-se diferença estatisticamente significativa entre $\mathrm{O}$ que é voz? Versus Corpo, postura e voz, Respiração, Articulação e ressonância e Expressividade. Da mesma forma, verifica-se essa diferença entre os módulos Cui- dados com a voz e Voz no trabalho docente versus Corpo, postura e voz, Respiração, Articulação e ressonância e Expressividade.

Em relação ao quesito NÃO COLOCOU EM PRÁTICA (Figura 1), verifica-se que houve diferença entre os módulos Corpo, Postura e Voz versus Respiração e Articulação e Ressonância.

Para o quesito TEVE DIFICULDADE (Figura 1), observou-se diferença estatisticamente significativa entre os módulos Respiração e Articulação e Ressonância. Houve uma proporção superior $(\mathrm{P}=9,73$; IC95\%=6,11 - 13,35) de professores que relataram dificuldade no módulo Respiração quando comparado ao módulo Articulação e ressonância $(\mathrm{P}=1,17$; IC95\%=0,14 - 2,48). 
Conteúdo

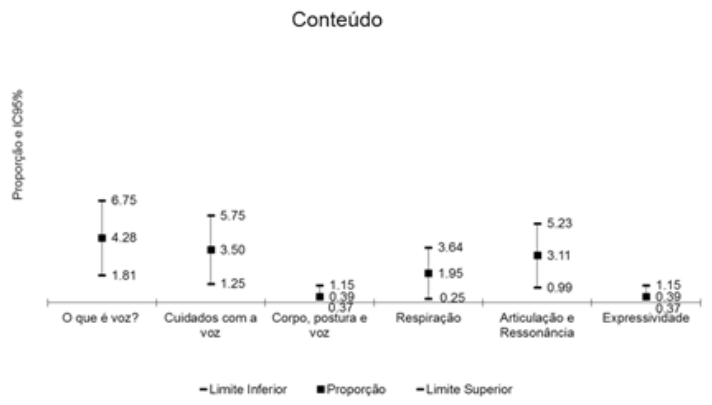

Não colocou em prática

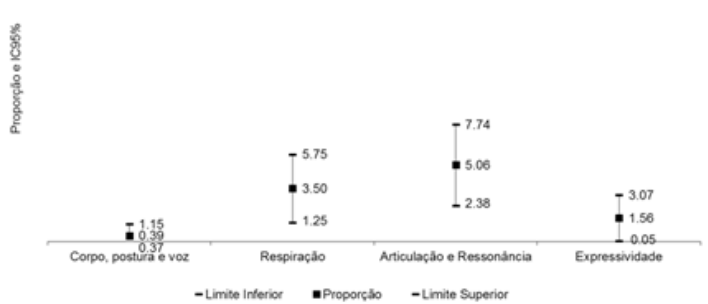

Colocousem pratica

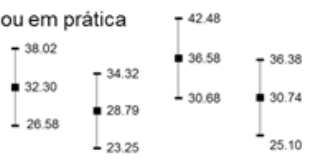

Figura 1. Comparação da proporção e seus respectivos IC 95\%, entre os módulos.

Observa-se na Figura 2 que, para o quesito ELOGIO, houve diferença estaticamente significativa entre o módulo Voz e emoção versus Expressividade, Articulação e ressonância, Corpo, postura e voz e O que é voz?. Verifica-se, também, que houve diferença entre o módulo Cuidado com a voz versus Articulação e ressonância, e Respiração versus Articulação e ressonância.

Quanto ao quesito SUGESTÕES (Figura 2), houve diferença entre o módulo Voz no trabalho docente versus $\mathrm{O}$ que é voz? e Corpo, postura e voz.
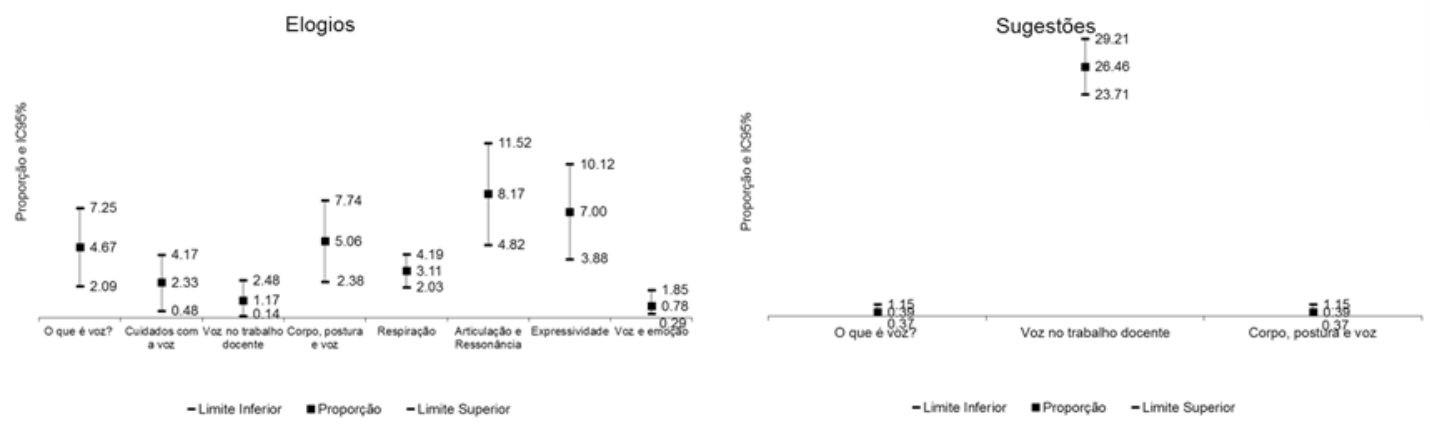

Figura 2. Comparação da proporção e seus respectivos IC 95\%, entre os módulos.

\section{Discussão}

A participação dos professores no curso promovendo o bem-estar vocal do professor foi avaliada considerando os relatos dos mesmos na modalidade dos fóruns. A participação foi efetiva, provavelmente pelo interesse deles como aprendizes do curso, e também por que tal atividade era obrigatória, para que o professor recebesse o certificado de conclusão, devendo ele participar de no mínimo cinco dentre os oito fóruns oferecidos. Essa prática de convalidar esse tipo de atividade tem sido 
utilizada em outras ações realizadas pela Prefeitura do Município de São Paulo ${ }^{10}$, e infelizmente é o que tem mantido a participação dos professores até a realização do último módulo.

Percebe-se pelos achados que todos os módulos receberam mais apontamentos referentes ao CONTEÚDO do que a FORMA. Dentre eles o denominado $\mathrm{O}$ que é voz? e Cuidados com a voz foram os mais referidos quanto ao CONTEÚDO. Provavelmente isso se deve por serem assuntos mais divulgados na mídia, principalmente por ocasião das comemorações ao Dia Mundial da Voz (16 de abril), em que fonoaudiólogos realizam Campanhas e nessas divulgam informações dessa natureza ${ }^{12},{ }^{13}$.

Interessante destacar que POMPEU (2016) ${ }^{14}$, ao analisar uma turma de Curso de mesma natureza do ora apresentado, utilizou um questionário em que perguntou qual módulo o participante considerou mais e menos interessante, e o Cuidados com a voz foi o eleito entre os mais interessantes.

Dentre os apontamentos registrados sobre o CONTEÚDO destacam-se os seguintes:

"Antes de mais nada, gostaria de registrar que o material e conteúdo do curso têm sido muito bons! De fácil leitura, mas um conteúdo consistente e interessante, elaborado de maneira dinâmica. Gostei!'”. (Módulo 2 - Cuidados com a voz)

"Gostei bastante do módulo e dos exercícios". (Módulo 5 - Respiração)

"Pra mim, de todos os módulos este foi o mais interessante em que aprendi muitas coisas que não sabia". (Módulo 6 - Articulação e Ressonância)

"Esse módulo é apaixonante, fiz os exercícios e foi muito interessante treiná-los". (Módulo 7 - Expressividade)

"O curso me proporcionou refletir sobre os impactos desses fatores na nossa voz. Acho que eu não teria feito essa associação e tantas outras, se não tivesse realizado o curso". (Módulo 8 - Voz e emoção)

Por outro lado, os módulos denominados Voz e emoção e Voz e trabalho docente não receberam nenhum apontamento quanto ao CONTEÚDO. Cabe destacar que na pesquisa de POMPEU $(2016)^{14}$, o módulo Voz e emoção foi considerado o menos interessante.

Quanto à FORMA, apenas por ocasião da apresentação do módulo $\mathrm{O}$ que é voz? um dos participantes disse "Que caminho eu preciso percorrer para participar do fórum, por que eu achava que já estava participando, mas não encontrei as perguntas e nem o texto para interagir". Cabe destacar que nas turmas anteriores vários participantes trouxeram queixas referentes à forma como o Curso era apresentado, destacando problemas quanto ao uso da plataforma Moodle e até mesmo da internet. Provavelmente com os ajustes realizados pelo grupo gestor, após discussão com profissionais mais experientes na utilização de educação à distância, foi possível no decorrer dos semestres, sanar as principais falhas. Atualmente o curso está sendo oferecido pela Escola Municipal de Saúde em que a versão 2.7.5 do Moodle é utilizada e, portanto, com mais subsídios para apresentar o curso.

Dentre os 403 apontamentos feitos com relação à APLICABILIDADE, 86,3\% foram referentes a COLOCOU EM PRÁTICA o que foi apresentado no Curso. Esse percentual parece se constituir num fato positivo, dado que a questão de colocar em prática algo que se aprende não é simples uma vez que depende de diversos fatores internos e externos, de diferentes naturezas (de ordem cultural, cognitiva, social, política, econômica) para que essa ação seja exitosa ou não ${ }^{15}$.

$\mathrm{Na}$ análise por módulo é possível destacar algo importante: de todos os módulos apresentados quatro deles apresentavam questões no fórum que diretamente perguntavam ao participante se ele tinha colocado em prática algum dos exercícios propostos (Módulos Corpo, postura e voz, Respiração, e Articulação e Ressonância). Dessa forma, era de se esperar que os três registrassem maior número de apontamentos realizados pelos participantes. Porém uma diferença pode ser apontada entre eles: dois deles, Respiração e Articulação e Ressonância, ao mesmo tempo em que receberam registro alto de apontamentos em que os participantes disseram ter colocado em prática o que foi apresentado, também foram aqueles que apresentaram apontamentos referentes a participantes não terem colocado em prática ou terem tido dificuldade para tal. Contudo, isso não acontece com o módulo Corpo, postura e voz em que a maioria apenas disse ter colocado em prática.

Essa diferença pode ter ocorrido por conta da temática apresentada no módulo Corpo, postura e voz ser menos subjetiva quando comparada a dos outros dois módulos. As questões referentes principalmente a Respiração e Ressonância são difíceis de serem ensinadas nos cursos de formação de fonoaudiólogos. A literatura aponta essa dificuldade ${ }^{16}$ e os professores de canto costumam até 


\section{Colocaram em prática:}

"Tenho feito fisioterapia e alongamento antes de sair para o trabalho. Dos exercicios apresentados coloquei em prática os de ombros e braços. Percebi um alivio ao fazê-los" (Módulo 4 - Corpo, postura e voz).

"Realizei os exercícios de respiração e me senti muito bem. Também fiz os exercícios de articulação, mas em casa, vou tentar realizar na escola antes de iniciar o trabalho" (Módulo 5 - Respiração).

"Ainda não havia parado para prestar atenção na articulação e ressonância; após realizar alguns exercícios percebi a fala mais clara e tranquila" (Módulo 6-Articulação e Ressonância).

Não colocaram em prática:

"Vou ser sincera, os exercícios ainda não se tornaram uma rotina em minha vida, até por que esqueci alguns" (Módulo 6 - Articulação e Ressonância).

"Ainda não coloquei nenhum em prática até a realização desse fórum, mas oportunamente começarei a colocar" (Módulo 5 - Respiração).

\section{Tiveram dificuldade:}

"Estou tentando fazer os exercícios, tive um pouco de dificuldade, mas acredito que praticando ficará mais fácil" (Módulo 5 - Respiração).

"Tenho realizado os exercícios conforme propostos. Noto que os de ressonância proporcionam uma maior dificuldade, mas sempre os procuro realizar" (Módulo 6-Articulação e Ressonância).

Cabe destacar que o grupo gestor por várias vezes pensou em realizar vídeo gravações dos exercícios para facilitar o entendimento, porém a versão da Plataforma Moodle utilizada nesse Curso não permite. Como dito anteriormente, atualmente a Plataforma utilizada é mais atualizada, fato que permitirá agregar aos módulos mais informações.

Outros dois módulos merecem reflexão: o módulo Expressividade e Voz e emoção. O primeiro aparece entre os que registraram maior percentual de apontamentos e esse destaque é importante, pois esse tipo de conteúdo ainda é pouco explorado nas ações de intervenção realizadas pelos fonoaudiólogos.

$\mathrm{O}$ registro de um dos participantes ilustra a importância:

\begin{abstract}
"Ao colocar os exercícios em prática pude notar como podemos alterar o sentido do discurso com a expressividade, entoação, fluência e quão importante é ficar atento a tudo isso". (Módulo 7 - Expressividade)

"Esse módulo é apaixonante, fiz os exercícios e foi muito interessante treiná-los”. (Módulo 7 - Expressividade)
\end{abstract}

Percebe-se que, no trabalho realizado com as questões relacionadas à Expressividade, os professores têm percebido o quanto a questão de como se fala interfere na relação ensino-aprendizagem, podendo aproximar ou afastar seus alunos. $\mathrm{O}$ uso de pausas, diferentes entoações, maior ou menor intensidade podem ser recursos utilizados pelos professores, em conjunto ao conteúdo do que se quer ensinar para o aluno. Em uma pesquisa ${ }^{18}$, investigaram, por meio de entrevista com 18 professores, os recursos utilizados para obter a atenção dos alunos em sala de aula. Dentre as estratégias mencionadas, foram destacados os recursos como linguagem bem estruturada, definição articulatória, variação de frequência e intensidade vocal, uso de pausas e ênfases, contato visual com os alunos, pedido de atenção ou silêncio, e uso de gestos.

O módulo Voz e emoção era um dos que perguntava diretamente ao professor que falasse a respeito da relação entre os fatores estressores presentes no seu ambiente escolar e se isso interferia na sua voz. O exemplo abaixo ilustra o apontamento de um dos participantes.

"Quando passo por situações estressoras, a primeira coisa que sinto é a voz falhar e tusso muito”. (Módulo 8 - Voz e emoção)

Quanto aos ELOGIOS e SUGESTÕES percebe-se que os professores destacaram os módulos de Respiração e o de Voz no trabalho. Como foi dito acima, o trabalho com as questões de respiração é complexo, principalmente com o sexo feminino que costuma apresentar o tipo respiratório alterado, mesmo entre os sujeitos que não apresentam alteração de voz.

"Gostei bastante do módulo e dos exercícios". (Módulo 5 - Respiração)

Outro aspecto que merece destaque é a necessidade de se manter os encontros presenciais, 
uma vez que nesses, dúvidas são esclarecidas e as práticas realizadas em conjunto.

"O encontro presencial 2 foi de fato maravilhoso, cheio de dicas e novas descobertas". (Módulo 5 - Respiração)

"Muito obrigada pelo empenho e pelas dicas passadas no segundo encontro! De fato, foi uma experiência MAGNÍFICA E INESQUECÍVEL!" (Módulo 5 - Respiração)

Destaque deve ser dado ao fato de os professores em sua maioria não terem em sua formação nenhuma informação a respeito dos cuidados com a voz ou de como utilizá-la da melhor forma. Enquanto atores, teleoperadores, radialistas participam de cursos, oficinas ou capacitações em que a temática Voz é discutida, professores iniciam sua atuação profissional sem nenhuma atenção a isso. Relatos dos participantes ilustram, de um lado, que mesmo com carga horária pequena (40 horas) o Curso proposto conseguiu mobilizar e sensibilizar os participantes; e de outro, o quanto o professor se sente "carente" de atividades voltadas a cuidar de si, uma vez que a oferta de cursos vão na maioria das vezes, na direção de ele entender e atender melhor seus alunos.

"O curso tem me ajudado muito, Obrigada!" (Módulo 6 - Articulação e Ressonância)

"Tenho aprendido muito com esse curso e desde já agradeço". (Módulo 6-Articulação e Ressonância) "O curso tem ajudado bastante no meu trabalho, pois a voz é o nosso instrumento de trabalho" (Módulo 6 - Articulação e Ressonância).

" $O$ estudo realizado neste módulo me fez conhecer e avançar ainda mais na busca de uma melhor qualidade da voz" (Módulo 6 - Articulação e Ressonância)

"Pra mim de todos os módulos este foi o mais interessante em que aprendi muitas coisas que não sabia" (Módulo 6 - Articulação e Ressonância).

"Primeiro quero parabenizar pelo material, muito conteúdo produtivo, adorei, não sabia nada do que $l i$, a respeito das vogais e consoantes, muito interessante" (Módulo 6 - Articulação e Ressonância). "Os exercícios propostos são excelentes e gostei muito de realizá-los" (Módulo 6 - Articulação e Ressonância).

"Muito bom esse módulo, foi o que mais me ajudou, porque os exercícios nos dão uma consciência maior de como produzimos os diferentes sons de vogais, consoantes e verificação na prática"(Módulo 6 Articulação e Ressonância).
"Todos estes exercícios têm sido bem válidos. Este curso tem me ajudado bastante" (Módulo 7 - Expressividade).

"Tenho aprendido muito com esse curso e utilizado os recursos nele apresentados. Só tenho a agradecer" (Módulo 7 - Expressividade).

"Estou adorando o curso! Muito bom" (Módulo 7 - Expressividade).

"Esse módulo é apaixonante, fiz os exercícios e foi muito interessante treiná-los" (Módulo 7 - Expressividade).

Ao finalizar, alguns aspectos merecem destaque. O primeiro é salientar o papel dos tutores no processo de sensibilização dos participantes do Curso. Frequentemente o grupo gestor levantou aspectos relacionados ao maior ou menor empenho dos tutores, aspecto esse que interfere no processo. As questões levantadas relacionadas ao sujeito que aprende, a relação entre aprendiz e tutor, assim como com as demais pessoas envolvidas podem fazer a diferença quanto à ação ser mais ou menos exitosa e dessa forma contribuir para que alguns grupos possam ter participado de forma mais efetiva que outros ${ }^{19}$.

Outro aspecto que merece destaque é o fato de os dados evidenciarem que a educação à distância auxiliou na sensibilização dos participantes quanto às questões da voz, constituindo-se em ação que pode ser mais e mais bem explorada pelos fonoaudiólogos, nas intervenções realizadas com professores. A EAD pode ter contribuído na formação dos participantes, uma vez que aproximou o professor do universo de seu aluno, lembrando que ao participar do Curso o professor ocupou o lugar de aluno ${ }^{20}$. Um dos aspectos favoráveis foi o rompimento de barreiras quanto ao espaço geográfico e tempo proporcionando conhecimento para um maior número de pessoas, sem que houvesse quebra do binômio ensino-aprendizagem, e vínculo professor-aluno. Esta experiência pôde contribuir para a Educação em Saúde, tornando o professor um agente de sua própria saúde ${ }^{21}$.

A comunicação presencial e à distância têm suas especificidades. Quando se utiliza a linguagem do computador, a interação é diferente de uma aula presencial, quando é possível se observar as expressões dos envolvidos no processo de ensino-aprendizagem. As ferramentas tecnológicas utilizadas nas aulas de EAD são diversificadas (slides, vídeos, links, textos, chat, fórum, etc.), porém não é possível observar a turma em tempo real, como em 
uma aula presencial. No ensino à distância, quanto às dificuldades e ritmo dos alunos, leva-se algum tempo para percebê-los, e para que isso não se torne um entrave, é importante que o tutor acompanhe a turma e caso perceba algo, não hesite em alterar a abordagem ${ }^{22}$.

Seria imprescindível uma nova avaliação desses participantes após um tempo de realização do Curso para analisar o que de fato continuam a colocar (ou não) em prática, considerando os aspectos apresentados nos módulos.

A avaliação do processo aqui apresentada dará subsídios para que o grupo gestor possa realizar ajustes principalmente no conteúdo de alguns módulos, lembrando que a cada turma nova avaliação deverá ser feita.

\section{Conclusão}

Os achados registraram a necessidade de se realizar ajustes no Curso a ser oferecido a novas turmas, com maior ênfase em módulos cujo conteúdo exige maior entendimento conceitual e posterior realização de práticas. A modalidade EAD alcançou seu objetivo, propiciando um momento de escuta (registro) das necessidades do professor, assim como uma reflexão por parte dele sobre sua prática e ambiente de trabalho.

\section{Referências}

1. Dragone MLS, Ferreira LP, Giannini SPP, Simões-Zenari M, Vieira VP, Behlau M. Voz do professor: uma revisão de 15 anos de contribuição fonoaudiológica. Rev Soc Bras Fonoaudiol. 2010; 15(2): 289-96.

2. Simões-Zenari M., Bitar ML, Nemr NK. Efeito do ruído na voz de educadoras de instituições de educação infantil. Rev Saúde Pública. 2012; 46(4): 657-64.

3. Giannini SPP, Ferreira LP. Distúrbio de voz e estresse no trabalho docente: um estudo caso-controle. Cad. Saúde Pública. 2012; 28(11): 2115-24

4. Biserra MP, Giannini SPP, Paparelli R, Ferreira LP. Voz e trabalho: estudo dos condicionantes das mudanças a partir do discurso de docentes. Saúde e Sociedade. 2014; 23(3): 966-78.

5. Pizolato RA, Rehder MIBC, Dias CTS, Maneghim MC, Ambrosano GMBA, Mialhe FL. Evaluation of the Effectiveness of a Voice Training Program for teachers. J Voice. 2013; 25(5): 603-10.

6. Pizolato RA, Rehder MIBC, Dias CTS, Maneghim MC, Ambrosano GMBA, Mialhe FL. Impact on quality of life in teachers after educational actions for prevention of voice disorders: a longitudinal study. Health Qual Life Outcomes. 2013; 11: 28 .
7. Luchesi KF, Mourão LF, Kitamura S. Efetividade de um programa de aprimoramento vocal para professores. Rev CEFAC. 2012; 44(3): 459-70.

8. Telles LCS, Ueda-Santos AR. Curso a distância para professores: Conhecendo os segredos da voz e da Expressividade. In: Ferreira LP, Andada e Silva MA, Giannini SPP, organizadoras. Distúrbio de Voz Relacionado ao Trabalho: práticas fonoaudiológicas. 1 ed. São Paulo: Roca; 2015. p. 169-182.

9. Barbosa PP, Ursi S. Motivação para formação continuada em Educação à Distância: um estudo exploratório com professores de Biologia.Revista Electrónica de Enseñanza de las Ciencias. 2019; 18(1): 148-72.

10. Ferreira LP, Giannini SPP, Esteves AAO., Ferreira RM, Souza SS, Souza TMT. Bem-Estar Vocal de Professores: Relato de Experiência do Programa Municipal De São Paulo. In: Ferreira LP, Andada e Silva MA, Giannini SPP, organizadoras. Distúrbio de Voz Relacionado ao Trabalho: práticas fonoaudiológicas. 1 ed. São Paulo: Roca; 2015. p. 135-141.

11. Ferreira LP, Chieppe D. Quando as práticas fonoaudiológicas são educativas. Distúb Comun. 2005; 17(1): 123-6.

12. Dornelas RD, Giannini SPP, Ferreira LP. Campanha da Voz: uma iniciativa para cuidados em saúde. Distúb Comun. 2014; 26(3): 606-11.

13. Dornelas RD, Giannini SPP, Ferreira LP. Dia Mundial da Voz em notícia: análise das reportagens sobre a Campanha da Voz no Brasil. CoDAS. 2015; 27(5): 492-7.

14. Pompeu ATS. Intervenção fonoaudiológica com professores: análise de uma proposta realizada na modalidade de Educação a Distância [dissertação]. São Paulo: Pontifícia Universidade Católica de São Paulo; 2016.

15. Pereira DSC. O ato de aprender e o sujeito que aprende. Const psicopedagógica. 2010; 18(16): 112-28.

16. Gava Jr W, Ferreira LP. Apoio respiratório na voz cantada: perspectiva de professores de canto e fonoaudiólogos. Rev. Cefac, 2010; 12(4): 551-62.

17. Sousa JMD, Ferreira LP. O uso de metáforas como recurso didático no ensino do canto: diferentes abordagens. Rev Soc Bras Fonoaudiol. 2010; 15(3): 317-28.

18. Servilha EAM, Monteiro APS. Estratégias para obter a atenção discente no contexto universitário: o papel da voz do professor. Distúrb Comun. 2007; 19(2)225-35.

19. Hack JR. Comunicação dialógica na educação superior a distância: a importância do papel do tutor. Signo y pensamento. 2010;29(56):114-23.

20. Lapa AB, Belloni ML. Educação a distância como mídiaeducação. Rev. Perspectiva. 2012; 30(1): 175-96.

21. Oliveira MAN. Educação à Distância como estratégia para a educação permanente em saúde: possibilidades e desafios. Rev bras enferm. 2007; 60(5): 585-9

22. Abreu RMA, Vieira CMS. Educação a distância: uma reflexão sobre a relação professor-tutor e estudante no processo de ensino e aprendizagem. Revista Intersaberes. 2016; 11(23): 284-303. 